
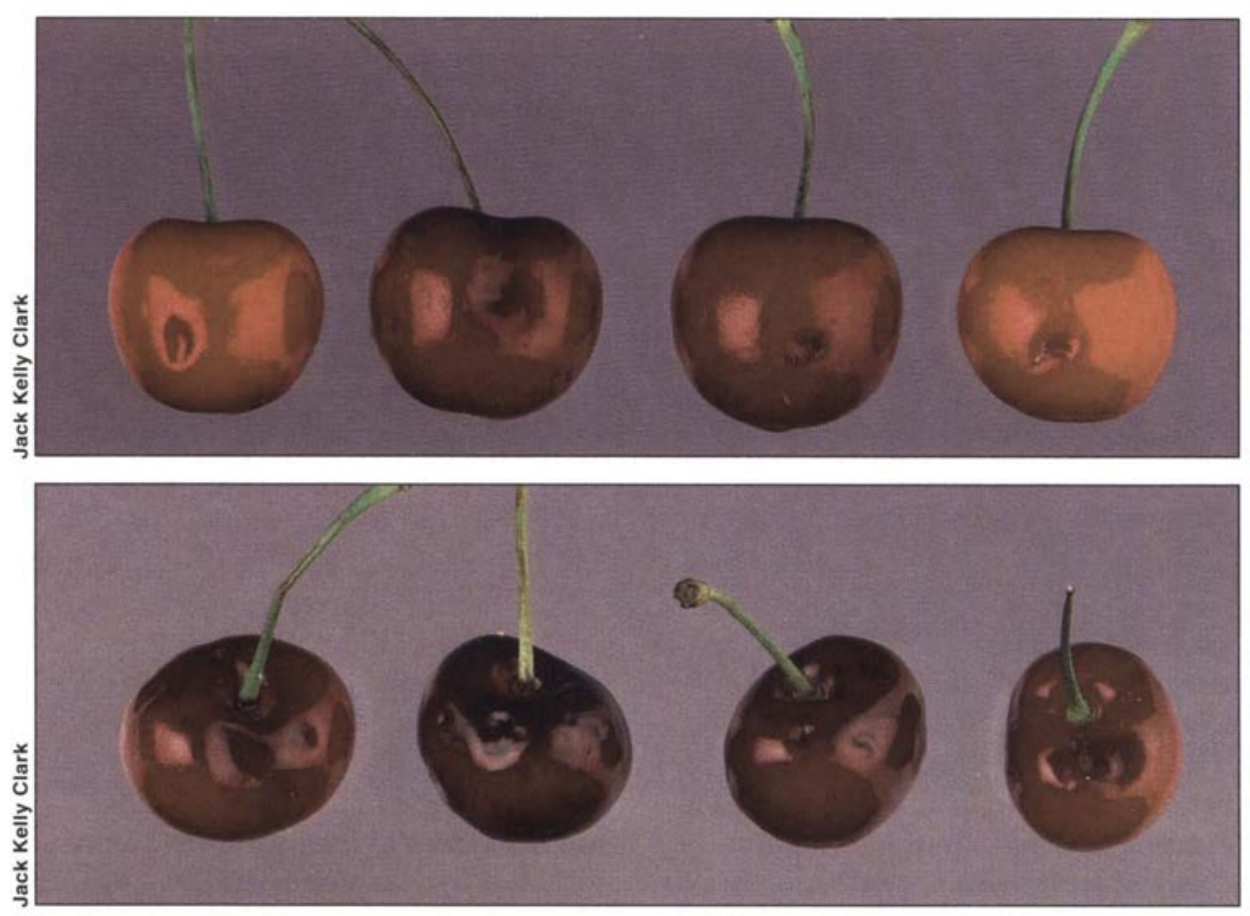

\title{
Packing-line modifications reduce pitting and bruising of sweet cherries
}

\author{
Joseph A. Grant J James F. Thompson
}

\section{Packing-house operations that cause sweet cherry fruit pitting or bruising damage were evaluated in a 4-year field study. Packing lines varied considerably in amounts of damage imparted to fruit, as did individual packing- house operations. Damage was reduced by slowing fruit speed in cluster cutters, by operating clus- ter cutters at high throughput rates and by reducing water-drop height in shower hydrocoolers.}

Cherry fruit are very susceptible to mechanical damage imparted during picking, packing and transport operations. After several days, storage at room temperature - or longer at lower temperatures - damaged fruit develop small sunken areas on the fruit surface, called pits, or larger flattened areas, called bruises. Pitting is thought to result from impacts with fruit stems or with hard surfaces, in which impact forces are concentrated in a small area of the fruit surface. Bruising, on the other hand, results when impact forces are spread over a large area. Results of our microscopic studies suggest that pitting is associated with injury, death and collapse of cells near the surface of fruit, while bruises develop when cells deep in the flesh are injured and die.

Pitting and bruising hasten fruit deterioration and detract from the appearance and salability of fruit in the marketplace. In both domestic and export markets, these defects are leading causes of product rejection and price adjustment requests by produce buyers and receivers.

Low soluble solids concentration, low fruit temperatures and small fruit size have been associated with greater susceptibility to mechanical damage in cherry, while preharvest gibberellic acid sprays and postharvest calcium dips have been shown to reduce damage susceptibility.
Pitting (top) and bruising (bottom) are the result of mechanical damage imparted during harvest or packing operations. These defects become visible with the passage of time as injured fruit cells collapse and die.

Sweet cherries are generally harvested by hand into metal picking buckets. The buckets are emptied into plastic or wood boxes holding 20 to 30 pounds of fruit, or into 4-foot-by-4foot-by-1-foot wood bins for transport to the packing shed. At the packing house fruit is dumped from bins, typically into a water-filled tank, and conveyed to operations where fruit is singulated, sized, sorted and cooled. Fruit intended for domestic shipment or export to countries not requiring methyl bromide fumigation for quarantine insect disinfestation is then cooled to $30^{\circ}$ to $32^{\circ} \mathrm{F}$ and packaged. Fruit to be fumigated for export is cooled to $45^{\circ}$ to $50^{\circ} \mathrm{F}$, accumulated in bins, fumigated, cooled to $30^{\circ}$ to $32^{\circ} \mathrm{F}$ and packaged (fig. 1).

Fruit moves rapidly through the various packing operations. In most cases, fruit is transferred directly between deleafers, cluster cutters and small-fruit eliminators, but is carried between other operations by dry conveyor belts or water flumes. Sloped elevators are used where fruit must be lifted between operations. Elevator belts usually have short plastic cleats, or "flights," at 8-to-12-inch intervals to prevent fruit from rolling back down the elevator.

Although picking and packing operations are known to cause damage leading to pitting and bruising, only limited research has been conducted to identify specific orchard and packinghouse operations that cause damage. In a 3-year study, researchers in Wash-

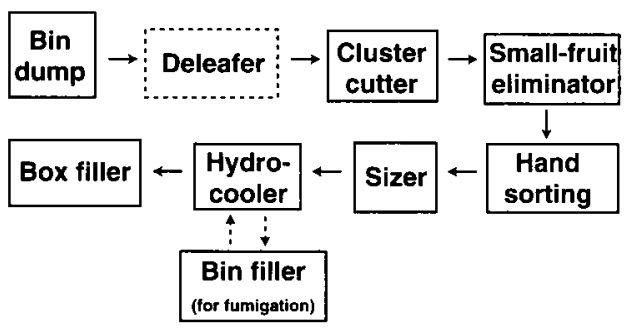

Fig. 1. Typical arrangement of California, Oregon and Washington sweet cherry packing operations. Fruit may be transferred directly between operations, or may be moved on conveyor belts or in water flumes. Some lines do not include a deleafing operation. 
ington found that $44 \%$ of fruit sustained bruising damage before entering the packing house and $58 \%$ was bruised during packing. Pitting damage was even higher: $79 \%$ of fruit was pitted before entering the packing house and $76 \%$ sustained pitting damage during packing. The researchers did not identify management practices or equipment designs that could reduce mechanical damage during orchard or packing-shed operations.

Fruit impacts with hard surfaces can cause damage. Growers and packing-house operators strive to minimize the number and height of drops at equipment transitions, and to cushion unavoidable impacts with water, foam rubber and other materials. Several studies have identified cluster cutting and fruit sizing as damaging operations, but did not investigate ways of modifying equipment design or operation to reduce damage.

Here we report the results of an initial damage survey (1992) and a 3-year project (1993, 1994 and 1996) designed to identify packing-house operations that cause mechanical damage to freshmarket sweet cherries and to develop recommendations for reducing damage.

\section{2 packing-house survey}

During the 1992 season, we sampled Bing cherries entering and exiting packing houses in California to measure damage levels typical of orchard and packing-house operations. We sampled fruit from 11 packing lines in 10 packing houses. Each line was sampled at least eight times during the harvest season. Packing houses were visited two to three times per week on a rotating basis, varied occasionally to accommodate the operating schedules of the participating houses. This procedure ensured that our samples were representative of fruit packed over the harvest season at each site.

Four samples of 25 to 40 fruit each were collected from field bins or boxes as they were emptied onto the packing line. After fruit from sampled containers reached the end of the packing line, a second set of four samples of 25 to 40 fruit each was collected at the end of the line, from corrugated fiberboard boxes packed for domestic sale or from bins containing fruit to be fu- migated for export shipment. We made no attempt to analyze individual handling procedures at each facility other than to note whether fruit arrived at packing houses in bins or in field boxes.

We stored samples in 1-pint plastic berry baskets at $50^{\circ} \mathrm{F}$ for 3 days to allow pitting and bruising damage to become visible. In preliminary tests, we had determined that these storage conditions would allow rapid expression of pitting and bruising damage for comparing samples. Following storage, 25 fruit from each sample were evaluated by a trained evaluator, who made separate counts of the number of pitted and bruised fruit in each sample. Spurred, doubled, sutured or decayed fruit were not included in our evaluations. Fruit were considered pitted if they had one or more small, distinctly sunken areas greater than 0.08 inch in diameter, or bruised if they had one or more large, soft, flat or indented areas on the fruit surface.

Damage during packing (pitting or bruising) was calculated as the difference between the amounts of fruit damaged before and after packing, expressed as a percentage of undamaged fruit present before packing. This percentage corresponds to the amount of fruit damaged during packing if all incoming fruit were undamaged, and allows comparisons among packing houses with differing levels of incoming damage.

An average of $27.8 \%$ of fruit was damaged prior to arriving at the packing house (table 1). There was no statistically significant difference among packing houses in the amount of fruit damaged prior to arrival. Fruit transported to packing houses in bins and boxes had similar $(P>0.05)$ average damage levels $(27.4 \%$ and $29.5 \%$, respectively).

The amount of fruit damaged during packing varied significantly among packing lines; with one line causing only $3.7 \%$ average damage and another causing $46.1 \%$. The two packing lines with the lowest damage during packing (lines 9 and 10b) had very different equipment designs. Equipment in packing line $10 \mathrm{~b}$ was relatively new and used water flumes to move fruit among operations, whereas line 9 was much older, with a dry box dump and dry conveyor-belt transfers. These results suggest that both old and new packing-house equipment can be operated in ways that ensure low levels of fruit damage.

\section{Individual line operations}

We conducted detailed fruit-damage studies during the 1993 and 1994 seasons at 10 packing houses processing Bing cherries: five located in California, three in Washington and two in Oregon. All of the packing houses used similar types of equipment, although differences were apparent in equipment arrangement, age, operation and maintenance. We collected single 30 - to 100 -fruit samples before and after each major operation at each facility. Our most common sampling points were (1) from bins or boxes before dumping, (2) on the conveyor carrying fruit out of the bin dump, (3) after the cluster cutter, (4) after the small fruit eliminator, (5) after the handsorting tables, (6) after the hydrocooler, (7) after the cherry sizer and (8) after box or bin filling. Each line was sampled three times on the same day. Samples were taken while packing lines were operating under normal conditions. A marker - several yellow fruit or a golf ball - was placed on the bin dump conveyor, and samples were

\begin{tabular}{|c|c|c|}
\hline $\begin{array}{l}\text { Packing } \\
\text { house } \\
\text { (line) }\end{array}$ & $\begin{array}{c}\text { Damage } \\
\text { before packing }\end{array}$ & $\begin{array}{l}\text { Damage } \\
\text { during packing }\end{array}$ \\
\hline & $\%$ & $\%$ \\
\hline 1 & 24.5 & 46.1 \\
\hline 2 & 31.4 & 34.9 \\
\hline 3 & 30.7 & 30.7 \\
\hline 4 & 26.3 & 25.6 \\
\hline 5 & 37.8 & 25.2 \\
\hline 6 & 25.5 & 24.8 \\
\hline 7 & 29.8 & 24.0 \\
\hline 8 & 22.6 & 12.7 \\
\hline 9 & 32.0 & 3.7 \\
\hline $10 a$ & 22.1 & 20.2 \\
\hline $10 b$ & 22.6 & 6.1 \\
\hline Average & 27.8 & 23.1 \\
\hline LSD* $^{*}$ & $\mathrm{NS}+$ & 16.5 \\
\hline \multicolumn{3}{|c|}{$\begin{array}{l}\text { "Fishers Protected LSD }(P<0.05) \text {, based on } \\
\text { one-way analysis of variance using packing } \\
\text { lines as treatments and } 8 \text { to } 11 \text { four-sample } \\
\text { means for each line as replications. } \\
\text { †No significant difference. }\end{array}$} \\
\hline
\end{tabular}



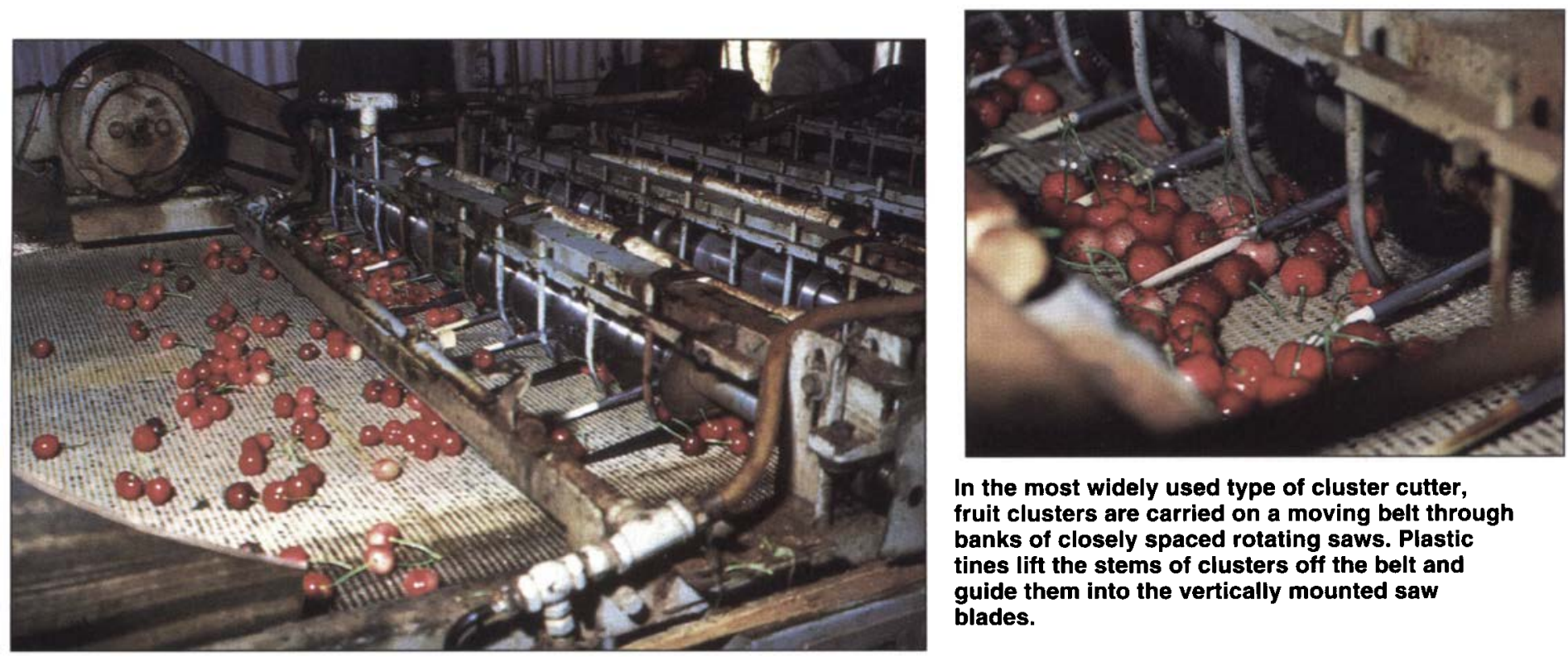

In the most widely used type of cluster cutter, fruit clusters are carried on a moving belt through banks of closely spaced rotating saws. Plastic tines lift the stems of clusters off the belt and guide them into the vertically mounted saw blades.

collected after the marker passed each sampling location. This procedure minimized error caused by bin-to-bin variation in fruit quality.

\section{Cluster cutters and belt speed.}

Cluster cutters in the 10 sampled houses were all saw-type units. Fruit is conveyed on a rubber or plastic belt past plastic tines, which are positioned at a narrow angle to the belt and pointed against the direction of fruit flow. Clusters of fruit are caught on the tines and the moving conveyor causes stems to move into rotating saws, which sever them. Fruit travel through the machine at the speed of the belt.

In four houses we measured the effect of varying the cluster-cutter belt speed on cherry damage. Belt speed was varied by changing belt-drive gear sprockets in three houses. In a fourth house, belt speed was varied by adjusting an electronic motor-speed controller. In 1996 we measured cluster-cutter damage at two houses that had installed newly designed cutters, one with flowing water instead of a belt to move fruit through the cutter, and another using a 3/8-inch-deep layer of water flowing on top of a moving belt to move fruit. At each site, fruit damage was determined using the same before-and-after fruit sampling procedures described previously.

Shower hydrocoolers. Rapid cooling of fruit from field temperatures to around $32^{\circ} \mathrm{F}$ is critical for preserving postharvest quality of cherries. Most packing facilities use shower-type hydrocoolers to accomplish this cooling, in which $32^{\circ} \mathrm{F}$ water is showered over fruit as it passes through the cooler on a slowly moving conveyor. We compared pitting damage with water-drop height in coolers at seven sampled houses using shower-type coolers. Water-drop height was measured from the bottom of the water distribution pan or diffusing screen to the top of the conveyor belt. Several coolers had fine-mesh diffusing screens installed below the shower pan releasing water onto fruit. In these coolers, water-drop height was measured from the screen to the conveyor.

Throughput rate. In two houses, we varied throughput rate to test its effect on fruit damage. Fruit throughput is the rate at which fruit is processed by a packing line; it is expressed as tons of fruit per hour of operation. Throughput was varied from 4.1, 9.0 and 11.3 tons per hour in one packing house and from 4.4, 6.7 and 10.2 tons per hour in another by changing the rate of bin dumping at the beginning of the line and the speed of the conveyor lifting fruit out of the bin dump. No other equipment speeds were changed. Samples of 100 fruit were collected for damage evaluation at various locations along the packing line. Each line was sampled twice at each of three throughput levels.

\section{Damage during packing}

We evaluated samples after 2 weeks of storage in loosely sealed plastic bags at $33^{\circ} \mathrm{F}$ and after 1 day at $68^{\circ} \mathrm{F}$. We found that fruit stored under these conditions had slightly greater expression of pitting and bruising damage, and had less tendency to lose moisture, soften and decay over extended storage than did fruit held in the open, mesh plastic baskets used in our 1992 survey. Fruit evaluations and damage calculations for individual operations were performed as described for our 1992 studies. Damage (pitting or bruising) imparted by individual packing operations was calculated as the difference in the amount of fruit damaged before and after the operation, expressed as a percentage of undamaged fruit entering that operation.

Pitting of fruit on arrival at the sampled packing houses averaged $34.9 \%$ (data not shown). Packing caused an average of $39.0 \%$ pitting damage over all houses, resulting in an average total pitting of $58.1 \%$ of packed fruit. Fruit averaged 19.0\% bruising on arrival at the packing houses, and packing bruised $9.9 \%$ of fruit, resulting in bruises on $27.1 \%$ of packed fruit overall. These findings are similar to those of our 1992 survey and to those of a 3-year cherry-quality study in Washington. Although some damage may occur prior to harvest, most prepacking damage is probably imparted during harvest activities and transport of cherries to the packing house. In 1994 we produced Englishand Spanish-language videotapes for training workers in proper picking 


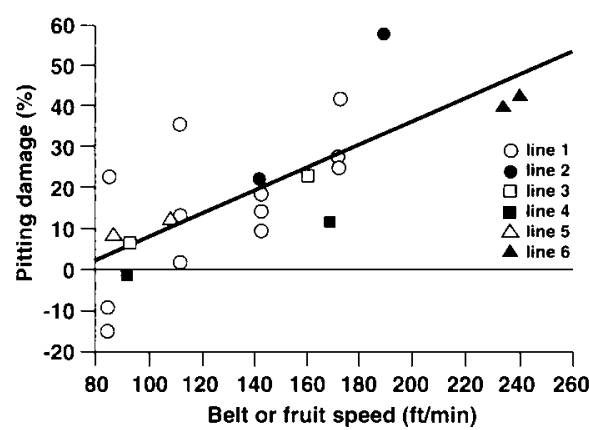

Fig. 2. Cherry pitting damage increased as fruit speed through cluster cutters increased $\left(r^{2}=0.58, P<0.0001\right)$.

and fruit-handling procedures (available from DANR Communication Services, UC Davis). Further research is needed to identify major sources and ways of mitigating harvest-related damage.

Among the individual packing operations evaluated, bin dumping, deleafing, small-fruit elimination, sizing, hand sorting and box filling imparted relatively little damage, while cluster cutting and hydrocooling caused the greatest damage (table 2).

Dumping and deleafing. Bin dumping and deleafing caused an average of $4.4 \%$ pitting damage and negligible bruising. Water bath bin dumps (fruit bins are tilted and fruit drops into a water-filled tank) were used in eight of the 10 houses. In these, a flighted inclined conveyor lifted the fruit out of the bath and conveyed them to the next operation. A dry dump and dry field-box dump, both to a flat belt conveyor, were used in the two other houses.

Deleafing employs an air stream blowing up through a bar conveyor to separate leaves from fruit. In our sam-

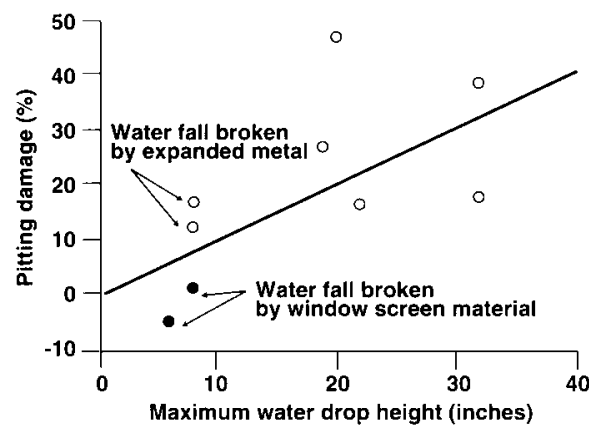

Fig. 3. Pitting damage was low in showertype hydrocoolers with small water-drop heights $\left(r^{2}=0.41, P=0.062\right)$.

pling locations this operation was combined with a transfer from the inclined bin dump conveyor to the deleafer bar conveyor. We sampled this operation separately in three lines and found that it caused no significant damage (data not shown). This seemed reasonable, because fruit moves slowly through deleafers and drops are short.

Small-fruit eliminators. Small-fruit eliminators consist of banks of paired, smooth, counter-rotating rollers that slope downward so that fruit slide between them. The gap between roller pairs increases slightly in the direction of fruit travel. Small fruit drop between the rollers and are not packed. Larger fruit are carried down the rollers and drop onto belts or into water flumes, which carry them to handsorting tables. Eliminators increased pitting damage by $1.0 \%$ and reduced bruising damage slightly. Sizers are similar in design and operation to eliminators, except that fruit are separated by size as they fall between rollers and are subsequently packed by size category. Sizers caused low levels

TABLE 2. Pitting and bruising damage caused by individual operations in 10 Bing cherry packing houses in California (5), Washington (3), and Oregon (2), 1993 and 1994

\begin{tabular}{|c|c|c|}
\hline \multirow[b]{2}{*}{ Operation } & \multicolumn{2}{|c|}{ Fruit damaged } \\
\hline & Pitting & Bruising \\
\hline & \multicolumn{2}{|c|}{ 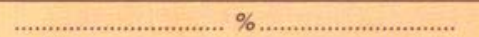 } \\
\hline Bin dump and deleafer & 4.4 & $-0.8^{*}$ \\
\hline Cluster cutter & 20.3 & 3.4 \\
\hline Small-fruit eliminator & 1.0 & 0.6 \\
\hline Hand sorting & 0.0 & -1.9 \\
\hline Hydrocooler & 18.6 & 9.6 \\
\hline Sizer & $-7.1+$ & 3.5 \\
\hline Box filling & -0.1 & 1.3 \\
\hline LSD $\ddagger$ & 11.5 & NS§ \\
\hline \multicolumn{3}{|c|}{$\begin{array}{l}\text { Negative damage values are generally due to sample variability. } \\
\text { †Reduced pitting in sizers is probably due to removal of more damage-susceptible small fruit by that operation. } \\
\text { fFishers protected LSD ( } P<0.05 \text { ) based on one-way analysis of variance using packing operations as } \\
\text { treatments and packing houses as replications } \\
\S \text { No significant difference }\end{array}$} \\
\hline
\end{tabular}


ries dropped 1 inch onto the tip of a tine had pitting damage. A cherry dropped 1 inch reaches a speed of 138 feet per minute. Cluster cutters are typically operated at belt speeds greater than 160 feet per minute.

Slowing cluster-cutter belt speed reduced pitting in the four houses where we compared high and low belt speeds (fig. 2, lines 1 to 4 ). In the two newly designed cutters with water alone or water and a belt to move fruit, a similar relationship between fruit speed and damage was observed (fig. 2, lines 5 and 6). Minimal damage levels were obtained only at speeds close to 80 feet per minute. Two packing-house managers indicated that they would have trouble keeping cluster cutters free of clogged fruit at speeds as low as 80 feet per minute, although we have occasionally observed cluster cutters operating near this speed. In practice, it may be best to equip cluster-cutter belts with electronic speed controls and adjust them to operate as slowly as possible without causing clogging.

Because we held fruit throughput constant, belt loading rates (number of fruit per unit belt area) increased with decreasing belt speed during our tests. In our fruit throughput tests, clustercutter fruit damage decreased with increased fruit throughput. We speculate that this was due to higher fruit loading rates. It is possible that some of the damage reduction associated with slower belt speeds was caused by increased fruit loading rates. However, we believe that it is reasonable to attribute at least a portion of the damage reduction at slower speeds to lower fruit-tine impacts caused by slower belt speeds.

Shower hydrocoolers. Showertype coolers (seven of the houses sampled) caused an average of $18.6 \%$ pitting damage and $9.6 \%$ bruising damage. Immersion coolers (two houses), in which fruit is cooled as it moves through a cold water bath, caused relatively little damage $(3.5 \%$ pitting, $-2.5 \%$ bruising). Shower-type hydrocoolers are known to damage some leafy vegetables because of water falling excessive distances from the water distribution pan onto the prod- uct. Pitting was low when water drop was less than 8 inches (fig. 3). Diffusing screens made only of expanded metal did not reduce damage as much as those made of expanded metal covered with fine-mesh plastic screening. Shower coolers that caused high levels of pitting damage also bruised a large per-

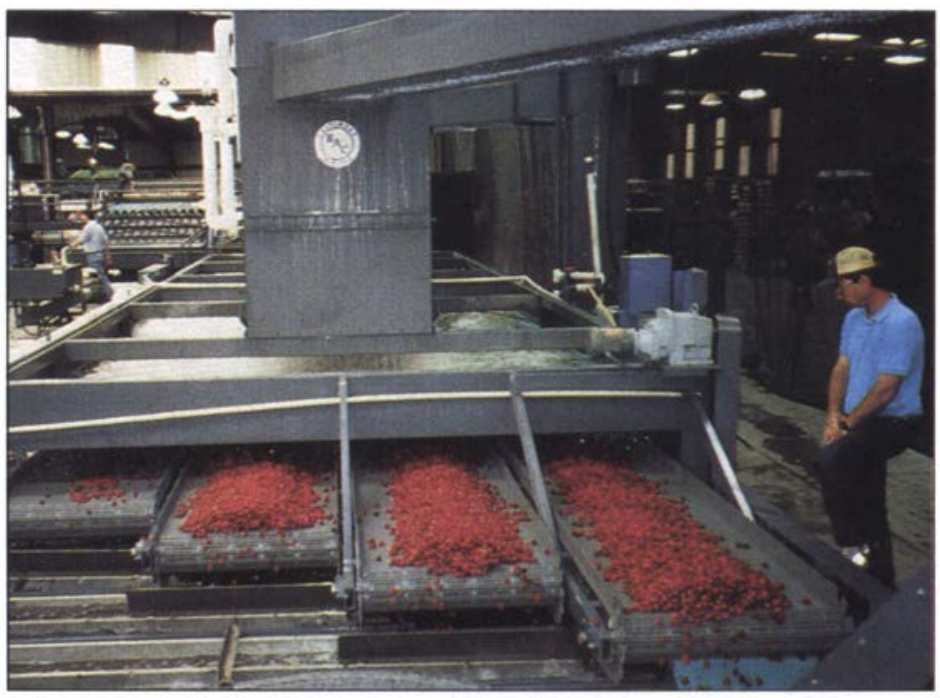
centage of fruit, so reducing water-drop height should reduce cherry bruising damage.

Two packing houses had 6-to-8inch drops between the cluster cutter and flighted conveyors carrying fruit to the eliminators. These drops caused very little damage (data not shown). However, a 10-inch drop out of the hydrocooler to a flighted conveyor at one packing house caused pitting in $27 \%$ of fruit and bruising in $7 \%$. Damage can be prevented by using water transfers, in which fruit falls into a water bath and a conveyor lifts the fruit out of the water to the next operation.

Throughput rate. There was no effect of rate of fruit throughput on damage imparted by all packing operations combined (data not shown). The only individual operation that showed an effect of fruit throughput was the cluster cutter. Fruit damage decreased as fruit throughput in the cluster cutter increased (fig. 4). We speculate that this occurred because high throughput rates reduce the probability that fruit will experience direct and damaging fruit-tine impacts as they pass through the cutter. Cluster cutters should not be operated at low fruit-throughput rates for prolonged periods, unless belt speed is low.

\section{Recommendations}

Most work focusing specifically on packing-house sources of damage has emphasized reducing the number and height of fruit drops to hard surfaces, or cushioning these drops, at equip-
A hydrocooler is used to rapidly cool cherries before they are placed into boxes.

ment transitions. To accomplish these objectives, recent packing-house designs have made increasing use of water flumes in place of conveyor belts and water troughs to receive fruit at elevators. We have identified packing operations that cause relatively little and shower hydrocoolers to cause the greatest damage. We recommend the following to help reduce damage in these two operations:

1. Design and operate cluster cutters at the highest throughput rates compatible with packing-house quality objectives and desired fruit flow through subsequent operations.

2. Operate cluster cutters at the lowest belt or fruit speed possible without causing clogging.

3. Minimize water-drop height in shower hydrocoolers. Install water distribution pans or diffusing screens as close as possible to the top of anticipated fruit levels.

J.A. Grant is Farm Advisor, UC Cooperative Extension, San Joaquin County; and J.F. Thompson is Agricultural Engineer, Department of Biological and Agricultural Engineering, UC Davis. The authors acknowledge the California Cherry Adrisory Board and Washington Tree Fruit Research Commission for their generous support of this project. damage and have found cluster cutters 